Physica C 282-287 (1997) 1035-1036

\title{
Thin films of high-T c superconducting cuprates by multi-target laser ablation
}

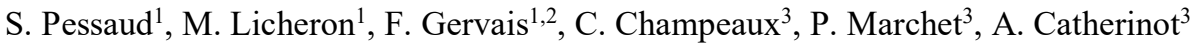 \\ 1 Centre de Recherches sur la Physique des Hautes Temperatures \\ CNRS, ID Avenue de la Recherche Scientifique, 45071 Orleans cedex 2, France \\ 2 Laboratoire d'Electrodynamique des Materiaux Avancés \\ Universite François Rabelais, Faculte des Sciences et Techniques, 37200 Tours, France \\ 3 Laboratoire "Materiaux Ceramiques et Traitements de Surfaces" \\ URA 320 CNRS-Faculté des Sciences, 87060 Limoges, France
}

\begin{abstract}
The preparation by a multi-target ablation method of new structures consisting in $\mathrm{CuO}_{2}$ planes textured via the $\mathrm{YBa}_{2} \mathrm{Cu}_{3} \mathrm{O}_{7}$ structure, is investigated. All films are superconducting. $\mathrm{X}$ ray data show that a new phase with more than two conseqcutive conductive planes might have been obtained. The onset temperatures which stay between 8 and $80 \mathrm{~K}$ indicate a probable underdoping.
\end{abstract}

\section{INTRODUCTION}

Ten years after the discovery of $\mathrm{YBaCuO}$, a lot of cuprate compounds, belonging to some ten families, exhibit superconductivity around $100 \mathrm{~K}$. The systematic lamellar structure of these compounds is based on the intergrowth of two different block layers: the (super)conducting layer and the charge reservoir layer [1]. The first one consists of an oxygen deficient perovskite structure in which $n \mathrm{CuO}_{2}$ planes alternate with planes of cations $\mathrm{M}(\mathrm{Y}, \mathrm{Ca}, \mathrm{Sr} . .$.$) . The charge reservoir block layer presents generally a rock-salt oxide structure including two$ different cations (A: $\mathrm{Cu}, \mathrm{Bi}, \mathrm{Tl}, \mathrm{Hg}$, and $\mathrm{B}: \mathrm{La}, \mathrm{Ba}, \mathrm{Sr}$ for example). The presence of the block layer appears necessary to observe superconductivity. The critical temperature increases with the number of consecutive $\mathrm{CuO}_{2}$ planes, at least up to three, in a number of compounds [1] and Tc decreases for four or five $\mathrm{CuO}_{2}$ planes. This decrease is attributed to a depletion of charge carriers in middle conducting planes. One way to obtain the infinite layer compounds or superconducting materials, is the laser ablation method which allows a layer by layer growth which gives artificial layered materials [2].

It is tempting to try to prepare new copper-oxide superconductors by the combination of infinite layers with charge reservoir block layers. We investigate the preparation of structures consisting in the mixing of $\mathrm{CuO}_{2}$ planes with $\mathrm{YBa}_{2} \mathrm{Cu}_{3} \mathrm{O}_{7}$ by multitarget laser ablation. Several compositions have been tested depending on the number of sequential pulses on two targets. We choosed to work with the number of pulses on the $\mathrm{YBa}_{2} \mathrm{Cu}_{3} \mathrm{O}_{7-\delta}$ target required to obtain one unit-cell on the substrate in the $c$ direction, and the number of pulses on a stoichiometric oxide of copper and calcium, strontium or barium target, necessary to tentatively add from one to five $\mathrm{CuO}_{2}$ planes. We present here some results obtained with the oxide of copper and calcium target.

\section{EXPERIMENTAL}

The targets are sintered pellets of superconducting $\mathrm{YBa}_{2} \mathrm{Cu}_{3} \mathrm{O}_{7-\delta}$ and a stoichiometric oxide of copper and calcium. The conditions of elaboration will be given elsewhere [3]. Thin films were obtained on $\mathrm{MgO}$ (100) single crystal which presents a weak lattice mismatch with $\mathrm{YBa}_{2} \mathrm{Cu}_{3} \mathrm{O}_{7-\delta}$, using pulsed laser deposition, with a $\mathrm{KrF}$ excimer laser $(\lambda=248 \mathrm{~nm})$. Inside the laser ablation chamber we have used, the operating conditions were optimized to get high-quality YBCO thin films, showing critical current up to $510^{6} \mathrm{~A} / \mathrm{cm}^{2}$ [4]. One therefore expects that these conditions optimized for $\mathrm{YBCO}$ will help this compound to play a «texturing» role for the formation of « infinite-layer» sequences. During the deposition process, the substrate is heated by a halogen lamp. Pure oxygen is introduced in the vacuum chamber at a pressure of $0.3 \mathrm{mbar}$. After deposition, the chamber is filled with oxygen at a pressure of 160 mbar. Thin films were characterized by X-ray diffraction using a Siemens diffractometer $\left(\mathrm{Cu} \mathrm{K}_{\alpha}\right)$. Data were obtained at $0.01^{\circ}$ intervals over an angular range $2 \theta$ of 5-60 ${ }^{\circ}$. The thermal evolution of electrical resistivity was measured by a standard DC four probe method in a closed cycle helium cryostat $(25-300 \mathrm{~K})$. Infrared spectra have been obtained with a Bruker IFS 307 Fourier spectrometer in the spectral range of 20 to $5,000 \mathrm{~cm}^{-1}$.

\section{RESULTS AND DISCUSSION OF SUPERCONDUCTING PROPERTIES}

Typical resisivity versus temperature data are shown in figure 1. All the films obtained are superconducting with onset temperature ranging between 68 and $80 \mathrm{~K}$ depending on the number of pulses on both targets. The resistivity at $300 \mathrm{~K}$ and the sharpness of the superconducting transition depend on the number of pulses on the two targets. At first sight, the range of critical temperature would suggest that no more than two consecutive conductive planes have been achieved. On the other hand, several phases have been indexed by X-ray 
diffraction [3], some of them have a $c$ parameter higher than $\mathrm{YBa}_{2} \mathrm{Cu}_{3} \mathrm{O}_{7}$ (about $13.5 \AA$ ). These results suggest a new phase (i) either with more than two consecutive conducting planes but underdoped or (ii) a thicker block reservoir with respect to $\mathrm{YBCO}$. One film clearly contains two phases which can be indexed like $\mathrm{YBa}_{2} \mathrm{Cu}_{3} \mathrm{O}_{7}(\mathrm{or}$ $\left.(\mathrm{Y}, \mathrm{Ca})(\mathrm{Ba}, \mathrm{Ca})_{2} \mathrm{Cu}_{3} \mathrm{O}_{7}\right)$ and $\mathrm{YBa}_{2} \mathrm{Cu}_{4} \mathrm{O}_{8}\left(\right.$ or $\left.(\mathrm{Y}, \mathrm{Ca})(\mathrm{Ba}, \mathrm{Ca})_{2} \mathrm{Cu}_{4} \mathrm{O}_{8}\right)$ but resistivity does not show several Tc onsets. The Tc $(70 \mathrm{~K})$ is neither representative of ideally-doped $\mathrm{YBa}_{2} \mathrm{Cu}_{3} \mathrm{O}_{7}(\mathrm{Tc}=92 \mathrm{~K})$ nor of $\mathrm{YBa}_{2} \mathrm{Cu}_{4} \mathrm{O}_{8}(\mathrm{Tc}=80 \mathrm{~K})$ nor $(\mathrm{Y}, \mathrm{Ca})(\mathrm{Ba}, \mathrm{Ca}) 2 \mathrm{Cu}_{4} \mathrm{O}_{8}(\mathrm{Tc}=90 \mathrm{~K})$. If calcium doping of $\mathrm{YBa}_{2} \mathrm{Cu}_{4} \mathrm{O}_{8}$ induces a $\mathrm{Tc}$ increase, conversely the superconducting critical temperature of $\mathrm{Y}_{1-\mathrm{x}} \mathrm{Ca}_{\mathrm{x}} \mathrm{Ba}_{2} \mathrm{Cu}_{3} \mathrm{O}_{7}$ decreases from about $92 \mathrm{~K}$ for $\mathrm{x}=0$ to about $66 \mathrm{~K}$ for $\mathrm{x}$ $=0.3$ [5]. For this film which show $\mathrm{X}$-ray signatures of $\mathrm{O}_{8}$ phase, the Tc appear compatible with Ca substitution onto the Y site provided that doping would not be optimal.

\section{CONCLUSION}

Superconducting films have been obtained by laser ablation on two targets, a superconducting YBCO one and a copper and calcium oxide one. Different phases appear, depending on the experimental conditions. Several phases are interesting in terms of possible larger number of consecutive conducting planes because of their $c$ parameter higher than that of $\mathrm{YBa}_{2} \mathrm{Cu}_{3} \mathrm{O}_{7}$ Some results are also compatible with a $\mathrm{Ca}$ substitution onto the $\mathrm{Y}$ site.

\section{REFERENCES}

1. M. Lagues, C. F. Beuran, C. Hatterer, V. Mairet, P. Laffez, X. M. Xie, X. Z. Xu, C. D. Cavellin, B. Eustache and C. Coussot, Coherence in High Temperature Superconductors p.70, World Scientific Deutscher Ricolevschi (1995).

2. Nobumasa, K. Horiuchi, K. Shimizu, T. Kawai, Physica C 257 (1996) 25.

3. S. Pessaud, M. Licheron, F. Gervais, C.Champeaux, P. Marchet, A. Catherinot, to be published.

4. C. Champeaux, P. Marchet, J. Aubreton, J.P. Mercurio, A. Catherinot, Applied Surface Science 69 (1993) 335.

5. A. Manthiram, S.-J. Lee and J.B. Goodenough, Journal of solid state chemistry 73 (1988) 278.

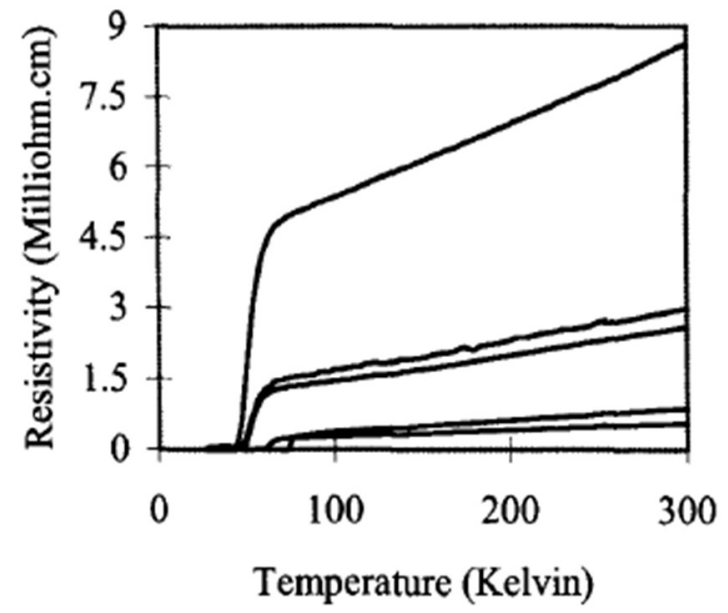

Figure 1 : Typical resistivity versus temperature for different films obtained with various sequences of pulses. The film in which $\mathrm{O}_{8}$ phase has been identified shows the lowest resistivity at $300 \mathrm{~K}$. 